\title{
Una imagen vale más que mil imágenes
}

\author{
María Rosario Aguilera Saavedra \\ Ronald Gustavo Durán Saucedo \\ Guadalupe Aramayo Solís \\ Juan Manuel Vaca Villarroel
}

\section{Correspondencia}

Rosario Aguilera

aguilera.rosario50@gmail.com

Hospital San Juan de Dios, Cardiología-Ecocardiografía, Bolivia

\author{
Recibido: 27/03/2020 \\ Aceptado:28/02/2021 \\ En línea: 30/04/2021
}

Citar como: Aguilera Saavedra M, Duran Saucedo R, Aramayo Solís G, Vaca Villarroel J. Una imagen vale mas que mil palabras. Rev Ecocar Pract (RETIC). 2021 (Abril); 4 (1): 8-10. doi: 10.37615/retic.v4n1a5.

Cite this as: Aguilera Saavedra M, Duran Saucedo R, Aramayo Solís G, Vaca Villarroel J. An image is worth than thousand images. Rev Ecocar Pract (RETIC). 2021 (Abril); 4 (1): 8-10. doi: 10.37615/retic.v4n1a5.

\section{Palabras clave \\ $\triangleright$ Drenaje venoso anómalo \\ $\triangleright$ Cimitarra \\ $\triangleright$ Cardiopatía congénita}

\section{Keywords}

$\triangleright$ Anomalous venous drainage

$\triangleright$ Scimitar

$\triangleright$ Congenital heart disease

\section{RESUMEN}

Mujer de 33 años, sin antecedentes de importancia, que debuta con clínica de disnea al realizar viajes a la altura. Se evaluó con múltiples exámenes de imágenes diagnosticándose el Síndrome de Cimitarra, una malformación congénita poco frecuente que se caracteriza por una conexión anormal entre las venas pulmonares derechas a la vena cava inferior, aurícula derecha o venas suprahepáticas. La evaluación de las técnicas de imagen multimodal tienen un rol importante en el diagnóstico y pronóstico de las patologías cardiovasculares, en este caso particular un método sencillo como la radiografía de tórax permitió sospechar su presencia.

\section{ABSTRACT}

33-year-old woman, with no significant history, who presents with dyspnea on sporadic trips to high altitude cities. She was evaluated with multiple imaging tests to diagnose Scimitar Syndrome. A rare congenital malformation characterized by an abnormal connection between the right pulmonary veins to the inferior vena cava, right atrium, or suprahepatic veins. The evaluation of multimodal imaging techniques has an important role in the diagnosis and prognosis of cardiovascular pathologies, however, in this specific pathology, a simple test like chest $X$ Ray can give the clues to suspect its diagnosis.

\section{Presentación del caso}

Se presenta el caso clínico de una mujer de 33 años, procedente de Trinidad Bolivia, sin antecedentes patológicos de importancia. Presenta un cuadro clínico de larga data (aproximadamente 3 años) con molestias al realizar viajes esporádicos por motivos laborales a la Ciudad de La Paz, Bolivia (3.640 ms. n. m). En último viaje, presentó disnea súbita con necesidad de soporte de oxígeno, sensación de desvanecimiento que no llega a pérdida del conocimiento y palpitaciones.

Fue referida de emergencia a la clínica particular de la Ciudad de La Paz donde la auxilian y le realizan los primeros exámenes complementarios, entre los que describe la presencia de un Ductus arterioso persistente. Posteriormente acude a nuestro centro hospitalario, para un eventual cierre percutáneo del ductus referido. Al primer contacto vemos a una paciente en buen estado en general, con signos vitales normales, $\mathrm{SO}_{2} 99 \% \mathrm{FC} 98$ Ipm, TA 110/70 y FR 16 rpm, soplo sistólico II/VI en segundo espacio inter- costal izquierdo. Resto del examen físico sin particularidades. Solicitamos un nuevo Ecocardiograma en nuestro centro, para determinar diámetros y presiones en el caso de cierre del ductus por vía percutánea. Se evidencia: cavidades cardíacas izquierdas con diámetros conservados, función diastólica normal, cavidades derechas dilatadas, insuficiencia tricuspídea leve a moderada con PSAP estimada $45 \mathrm{mmHg}$, dilatación de arteria pulmonar e insuficiencia pulmonar leve.

Se descarta el diagnóstico de ductus y se solicita ecocardiograma transesofágico en busca de shunt izquierda-derecha. Nuevamente no concluyente (Videos 1 y 2).

Con tres estudios ecocardiográfícos en su haber y sin diagnóstico preciso, se decide realizar angiotomografía de tórax, con técnica de reconstrucción en la cual se pudo objetivar en vistas axiales (Vídeo 3) y coronales (Vídeo 4) la presencia de sobrecarga derecha con drenaje anómalo de venas pulmonares derechas por una vena descendente a la vena cava inferior. 
La imagen volumétrica muestra también con precisión los hallazgos (Figura 1). Curiosamente la paciente nunca tuvo una radiografía de tórax (Rx) en el pasado (Foto 2)

\section{Estudio por imagen}

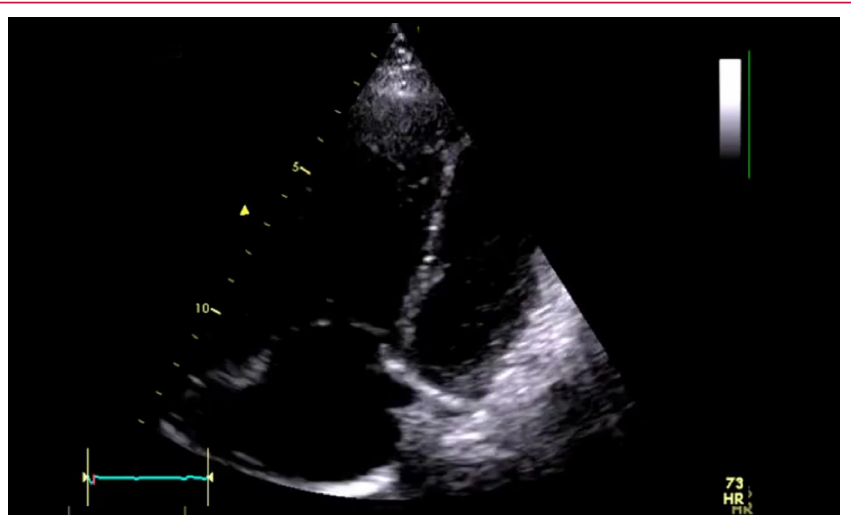

Vídeo 1. Vista de 4 cámaras apical de eco transtorácico, eco transesofágico que muestran dilatación de las cavidades derechas sin defecto septal interatrial visible

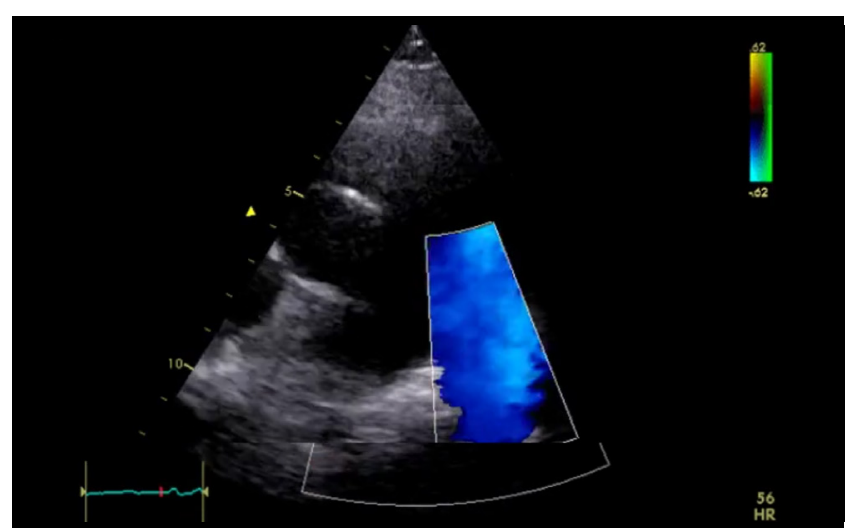

Vídeo 2. Eje corto de la arteria pulmonar, se observa dilatación del tronco y sus ramas, hay flujo circular en el tronco en sístole (azul y rojo)

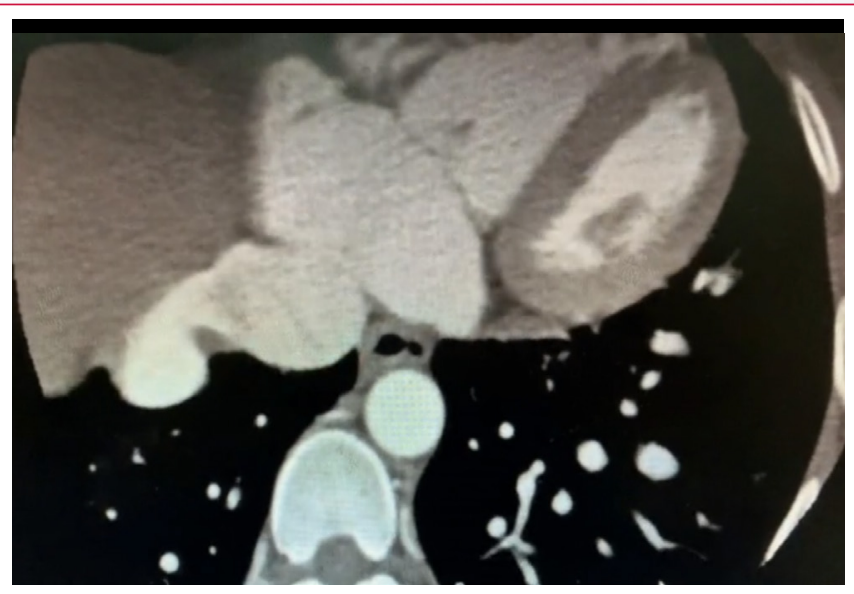

Vídeo 3. Vistas axiales de tomografía que muestran las venas pulmonares derecha que no llegan a la Al y que drenan a cava inferior

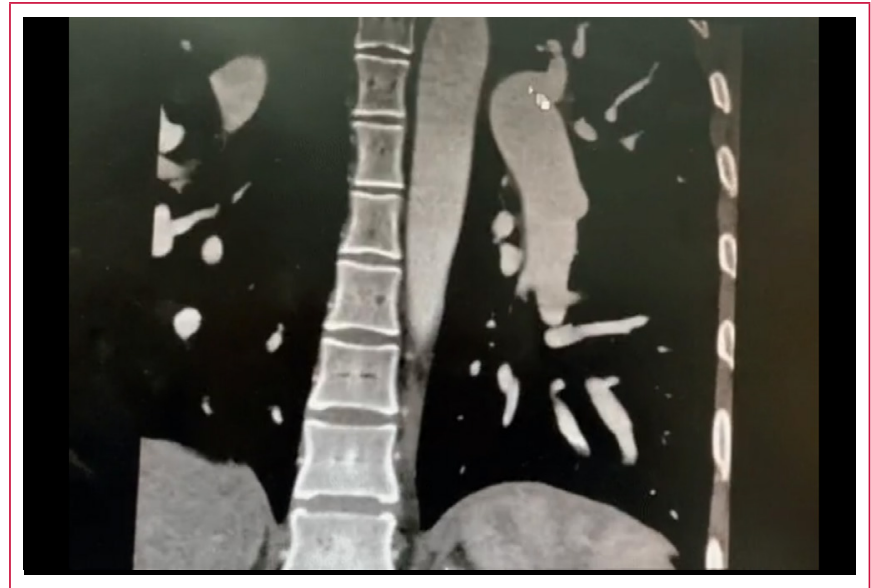

Vídeo 4. Vistas coronales de tomografía que muestran con más detalle el colector venoso derecho drenando a vena cava inferior

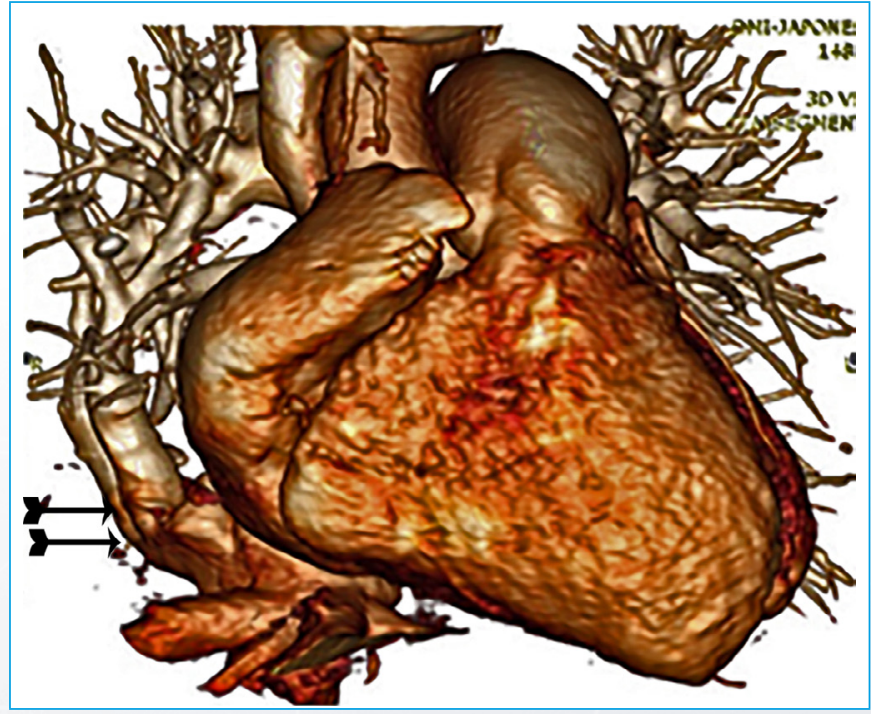

Figura 1. Imagen volumétrica tomográfica que muestra la dilatación de cavidades derechas y arteria pulmonar y el drenaje anómalo de venas pulmonares derechas con el colector venoso descendente drenando en cava inferior

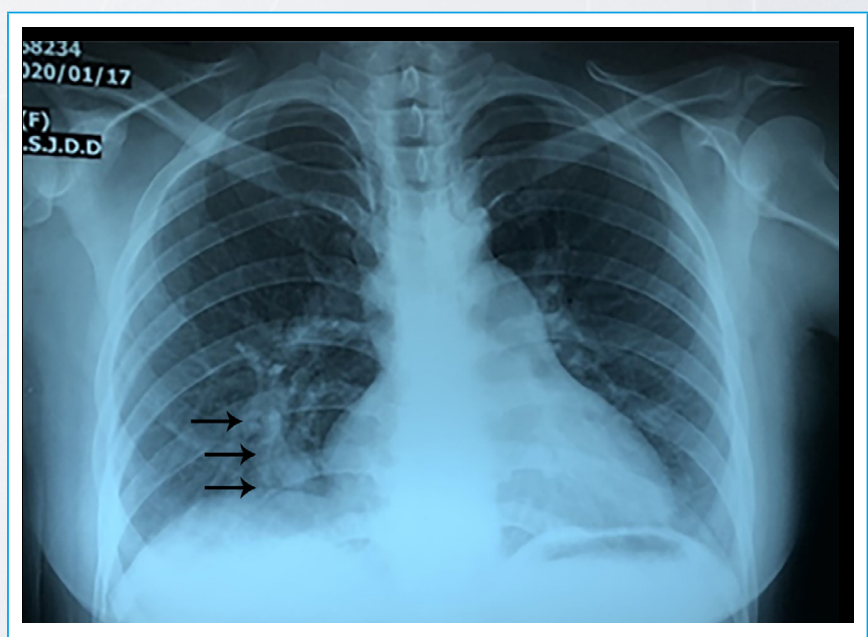

Figura 2. Silueta cardíaca de forma curiosa, arco pulmonar prominente. Las flechas muestran la vena anormal descendente con morfología curva (signo de la cimitarra) 


\section{Discusión}

El síndrome de la cimitarra se caracteriza por una conexión anormal entre una o más venas pulmonares derechas y el sistema venoso sistémico. Este suele asociarse a: hipoplasia del pulmón derecho, secuestro pulmonar, persistencia de vena cava superior izquierda y dextroposición cardíaca. El nombre del síndrome deriva de la imagen radiográfica de una opacidad creada por una de estas venas anómalas, generalmente la más desarrollada. Esta sombra se extiende desde el borde lateral superior del pulmón derecho a una localización medial y aumenta su calibre a medida que desciende a través del ángulo cardiofrénico; la apariencia de esta imagen parece una cimitarra, una palabra que proviene de la derivación italiana scimitarra, del shamshir persa, y que se refiere a cualquier sable curvo musulmán u oriental

La vena en cimitarra generalmente drena hacia la porción hepática de la cava inferior, pero también puede desembocar en las venas suprahepáticas, la vena porta, la vena ácigos o directamente en la aurícula derecha (provocando un cortocircuito de izquierda a derecha) $)^{(3)}$.

Constituye el $0.5-2 \%$ de las cardiopatías congénitas y el 3-5\% de los casos de retorno anómalo de venas pulmonares. Se ha descrito una incidencia de 1-3 casos por cada 100,000 recién nacidos vivos ${ }^{(1-2)}$

En la literatura hay descritas dos formas de presentación, la infantil (menores de un año) y la adulta. Incluso algunos autores clasifican un tercer grupo, el asociado a otras cardiopatías congénitas, en las que las más frecuentes es la comunicación interauricular $(25 \%)^{(3)}$. La variante infantil presenta peor pronóstico y síntomas más severos, mientras que, en la forma adulta, de mejor pronóstico, hasta un $75 \%$ se presentan asintomáticos, y en ellos el diagnóstico es incidental ${ }^{(2-5)}$.

La literatura nos habla de que la presencia del signo radiológico de la cimitarra puede encontrarse entre 57 y $74 \%$ de los pacientes ${ }^{(4,5)}$.

Las imágenes multimodales asociadas a un buen juicio clínico son de vital importancia en el manejo de patologías cardíacas simples y complejas.

En el presente caso queremos destacar cómo métodos complementarios sencillos y de bajo costo, como un electrocardiograma o una radiografía de tórax, asociados a una historia y examen físico prolijos, pueden ayudarnos a realizar diagnósticos certeros que nos permitan la utilización adecuada de los recursos, los cuales muchas veces no están disponibles o nos son accesibles nuestros países.

\section{Conclusión}

El síndrome de la Cimitarra, dado por conexión anómala entre las venas pulmonares derechas y el sistema venoso sistémico, es una cardiopatía congénita infrecuente en la cual debe prevalecer la sospecha clínica e imagenológica, resultando las imágenes cardiacas y, en especial la tomografía, herramientas fundamentales en el diagnóstico preciso.

\section{Ideas para recordar}

- El Síndrome de la Cimitarra es una cardiopatía infrecuente

- Debe estar presente en el diagnóstico diferencial de las sobrecargas de cavidades derechas

- La Radiografía de tórax puede ser una clave inicial para el diagnóstico

\section{Bibliografía}

1. López-Galletti N. Signo de la cimitarra. Rev Argent Radiol. 2013; 77:71-2.

2. Yarisa Sujey Brizuela, et al. Bol. Med. Hosp. Infant. Mex. 2011;68 (6): 451454

3. Vida V.L., Padrini M., Boccuzzo G., Agnoletti G., Bondanza S., Butera G, et al. Historia natural y evolución clínica de los pacientes con síndrome de la cimitarra: un estudio multicéntrico de la Sociedad Italiana de Cardiología Pediátrica. Rev Esp Cardiol. 2013; 66:556-60.

4. Ngai, C., Freedberg, R. S., Latson, L., Argilla, M., Benenstein, R. J., Vainrib, A. F. Saric, M. (2018). Multimodality imaging of scimitar syndrome in adults: A report of four cases. Echocardiography. doi:10.1111/echo.14124.

5. Vida VL, Padrini M, Boccuzzo G y col. Historia natural y evolución de los pacientes con síndrome de cimitarra "no corregido". Rev Esp Cardiol 2013; 66 (7) : 556-560. https://doi.org/10.1016/j.recesp.2013.03.011. 